\title{
Digital Pedagogy implementation in Engineering using SMART Mobiles
}

\author{
Radeep Krishna Radhakrishnan Nair ${ }^{1}$,Nagaraj Ramrao ${ }^{2}$, Sivapragasam Chandrasekaran ${ }^{3}$, Anish Nair ${ }^{4}$, \\ Sivakumar Pothiraj ${ }^{5}$ \\ ${ }^{1}$ Department of Electronics and Communication Engineering, Kalasalingam Academy of Research And Education, \\ Krishnankoil \\ ${ }^{2}$ Department of Electronics and Communication Engineering, Kalasalingam Academy of Research And Education, \\ Krishnankoil \\ ${ }^{3}$ Department of Civil Engineering, Kalasalingam Academy of Research And Education, Krishnankoil \\ ${ }^{4}$ Department of Mechanical Engineering, Kalasalingam Academy of Research And Education, Krishnankoil \\ ${ }^{5}$ Department of Electronics and Communication Engineering, Kalasalingam Academy of Research And Education, \\ Krishnankoil \\ ${ }^{1}$ r.radeepkrishna@klu.ac.in \\ ${ }^{2}$ nagaraj.ramrao@gmail.com, \\ ${ }^{3}$ sivapragasam@klu.ac.in, \\ ${ }^{4}$ anish@klu.ac.in, \\ ${ }^{5}$ siva@klu.ac.in
}

\begin{abstract}
:
The mobile learning paradigm has significantly started influencing the global education sector, the outcome of which has reflected in the increased usage of mobile for learning by the students for online classrooms. Further, there is a need to better understand as well as individual and contextual level factors which are related to students mobile usage in learning activities. Hence, it is imperative to consider the usage of mobile with digital pedagogy. This study explores individual and contextual predictors of mobile usage among undergraduate students in the stream of engineering. Learning intent is defined as the personal importance that the students ascribe to use mobile for online classes. The participants included are 1004 engineering undergraduates.The regression models has been developed to examine the relationship between mobile usage with respect to new proposed model of Mobile Infographic Pedagogy (MIP).It is observed that the study analysis depicts that the Learner centric is a more significant parameter when mobile infographic pedagogy is utilized. The model reported in this paper can easily be applied by all the faculty members in any institution to help the students improve their attention in the process of teaching-learning.
\end{abstract}

Keywords: Mobile Phone Usage, Mobile Infographic Pedagogy, Regression, Neuro Fuzzy Modelling.

\section{Nagaraj Ramrao}

Department of Electronics and Communication

Engineering, Kalasalingam Academy of Research And

Education,Krishnankoil-626126

nagaraj.ramrao@gmail.com
Earlier, the distant education is a part of Desktop Computer learning and systems are needed at all terminal places for the users. When the e-Learning has become a subset of the modern engineering classrooms, it is imperative that the flow needs to be redesigned for better learning activity in online mode. The entry of mobiles in the education sector from the online classrooms to blended learning has revolutionized the usage of data in shorter period by bringing all the stakeholders close to one platform, the mobile platform. The digital pedagogy is very important to define and conceptualize the level of usage in the modern online learning and with advent of mobile phone, the importance of Mobile Infographic Pedagogy [MIP] would be essential. It guides to personalised learning, ubiquitous learning etc. Here, the Learner can be sitting at different locations and the platform of mobile is used. The presence of learner is verified in virtual mode irrespective of the location and the only factor that is cared about is the 'Mobile Data connection' which brings the unique features like scalability, portability, and mobility. The changes in learning from conventional to e-learning using mobile phones have made far reaching changes to the way the classes are held today. Consequently, the focus of this paper is mostly on the mobile infographic pedagogy to tackle different aspects of mobility and connectivity.

\section{Related Works}

\section{A. e-Learning Intent}

The learning intent is termed as the effort taken to address the learning characteristics. A part of learning characteristics of smart learning is an e-Learning Intent. The efforts towards smart learning are highly situated and authentic (Lias et.al., 2011).The components of smart learning are responsiveness and adaptiveness to changing learning situations, environments, and activities (Hwang 
et.al.,2014), (Yu et.al, 2016). The Self-goal directed, learner creative centric and empowerment along with collaboratives, interdependent and high socially oriented scheme are also important smart learning factors (Kim et.al.,2013),(Middletonet.al.,2015).High customization as well as personalisation is also a part of the intent ( Hwang et.al, 2014). The e-Learning is a form of logically interactive and full dynamic oriented (Huang et.al, 2012). Hence, the e-Learning platform can also be categorized as platform based on seamless and oriented on contextual (Scot et.al., 2014).

\section{B. Self Confidence in Mobile usage}

Studies have been carried out to perceive the relationship of mobile phone usage pattern with self-esteem and loneliness of students especially girls students (Azra Tabassum et.al., 2018). The studies show that the girls with high mobile usage pattern have reported less self-esteem and faced high loneliness whereas the girls with low mobile usage have reported more self-esteem and low loneliness. This model referred from other models like the Problematic Use of Mobile Phone (PUMP) Scale developed by Lisa J. Merlo, Amanda M. Stone, and Alex Bibbey (2013).Consequently, self confidence is an important attribute in the study of mobile usage in e-learning platform and it can be measured as a value for an outcome.

\section{Methodology}

The Fundamental parts of Digital pedagogy have been explained in various forms and in which, the concept of Technological Pedagogical Content Knowledge [TPCK] is more formidable (Koheler and Mishra, 2016) and the concept of its application includes other areas like classroom products where e-learning is a very important requirement (Radhakrishnan Nair et.al,. 2019).

With the advent of Mobile phone, the pedagogies have been changed to mobility and suitability. It has potentially disrupted the field of innovative learning schemes and brought a paradigm shift in the Engineering Classes.

For sharing of e-Learning materials which are normally done with hardcopy materials, the system uses new templates by bringing higher education into the doorsteps of Mobile based

The Digital Pedagogy is applied for mobile e-Learning and it is known as the Mobile Infographic Pedagogy. Despite many predictions, the use of mobile devices in Educational Institutions has not been properly studied as per latest trends. As a result, the new scheme of Mobile Infographic pedagogy can be utilized at all places including in online classrooms and labs.

The five important principle characteristics of Mobile Infographic pedagogy are Location, Contextual, Learner
Centric, Collaborative and Dynamic Interaction. Based on these characteristics, the study has focused on the formation of research Questionnaire.

The Research Questionnaire is formed as shown in Table1.

Table1. Survey for Mobile Infographic Pedagogy

\begin{tabular}{|l|l|l|}
\hline S:N & Level & Questionnaire \\
\hline $\mathbf{1}$ & Input & $\begin{array}{l}\text { Rate the level of location and reliability of mobile } \\
\text { usage } \\
\text { [ Location and Reliability] }\end{array}$ \\
& & $\begin{array}{l}\text { Rate the level of seamless and contextual } \\
\text { [ Seamless and Contextual] }\end{array}$ \\
& $\begin{array}{l}\text { Rate the level of Learner Centric Activity } \\
\text { [Learner Centric] }\end{array}$ \\
& $\begin{array}{l}\text { Rate the level of collaborative } \\
\text { [Level of Collaborative] }\end{array}$ \\
& $\begin{array}{l}\text { Rate the level of Interactive and dynamic } \\
\text { [Interactive and Dynamic] }\end{array}$ \\
\hline $\mathbf{2}$ & Output & $\begin{array}{l}\text { Rate the level of mobile based learning } \\
\text { Confidence } \\
\text { [Mobile based learning confidence] }\end{array}$ \\
\hline
\end{tabular}

\section{Experimental Analysis}

Data collected in the form of survey from 1004 students from first year, second year, third year and fourth year engineering students of Kalasalingam Academy of Research and Education. Figure 1 shows that among the data collected, $62 \%$ respondents are males, and $38 \%$ respondents are females.

From Figure 2, it is clear that 33\% respondents are from first year, 35\% from second year, $22 \%$ respondents from third year and $10 \%$ from fourth year. For the study analysis, Regression Analysis and Neuro Fuzzy Modelling, which is a technique to model and investigate the relationship between two or more variables, have been used. 


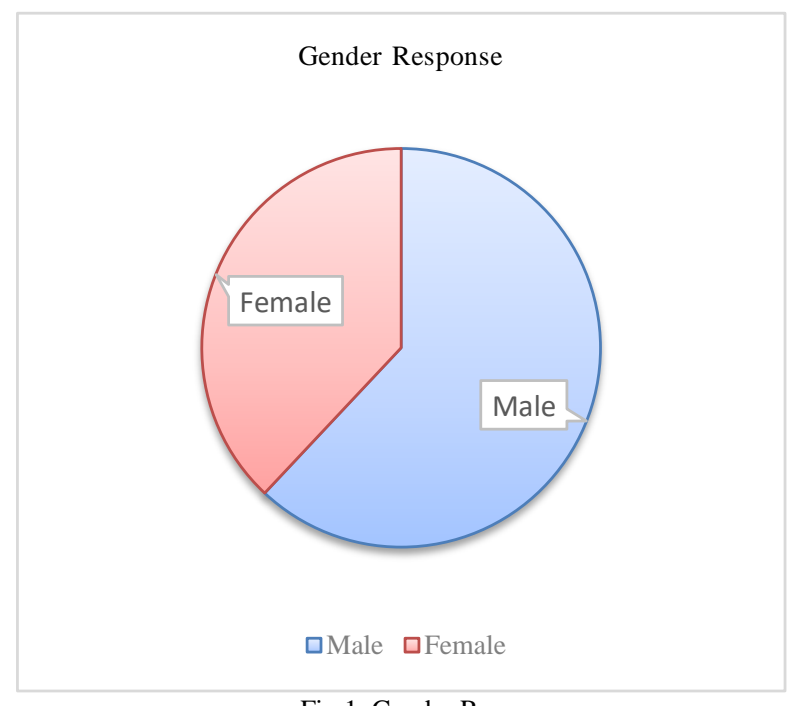

Fig 1. Gender Response

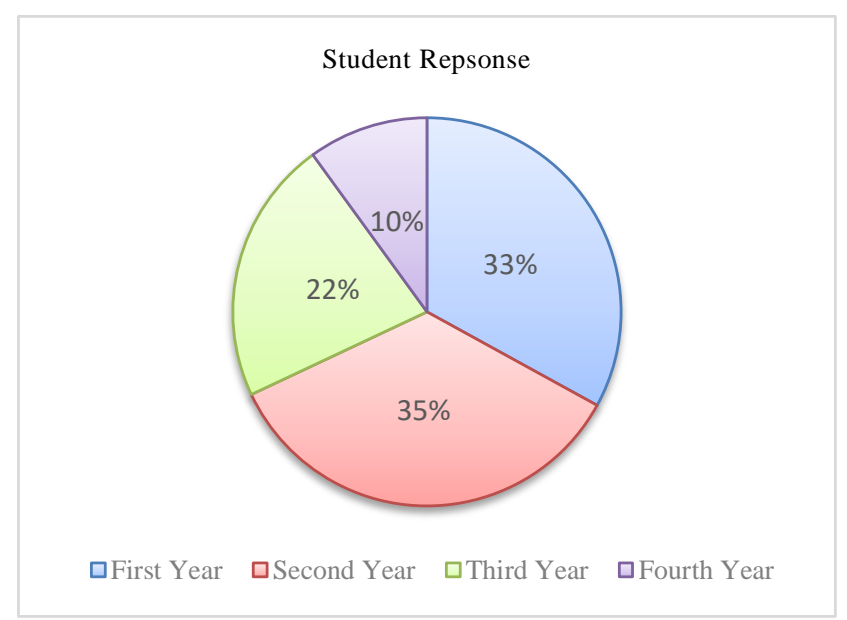

Fig 2. Student Response

The statistical model is used for one of the predictions among two and the other one is Neuro Fuzzy Model. The Flow design of the study process is needed and hence, it is categorized as shown in Figure 3.

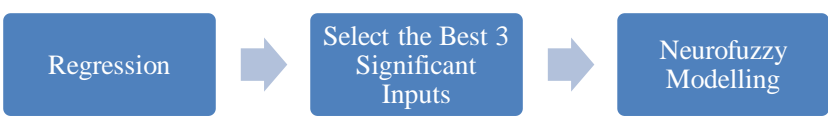

Fig 3. Flow of the proposed study

The Regression is used here for testing the data. The Regression Technique is performed with Minitab. The Regression Technique is performed as a form of predictive modelling technique and it investigates the relationship between dependent variable and independent variable. This predictive model is utilized to understand 5 inputs and in which, one of them is more significant in this study.

\section{Results and Discussions}

Initially, the regression is implemented for the input data as referred in Table 1. Total Data obtained is 1004 and they are placed in the regression model.

\section{Regression Equation \\ Rate mobile based learning confidence \\ $=-0.00489+0.200432$ Location and Realiability \\ +0.200190 Seamless and Contextual \\ +0.199673 Learner Centric \\ +0.200392 Collaborative \\ +0.203356 Interactive and Dynamic(1)}
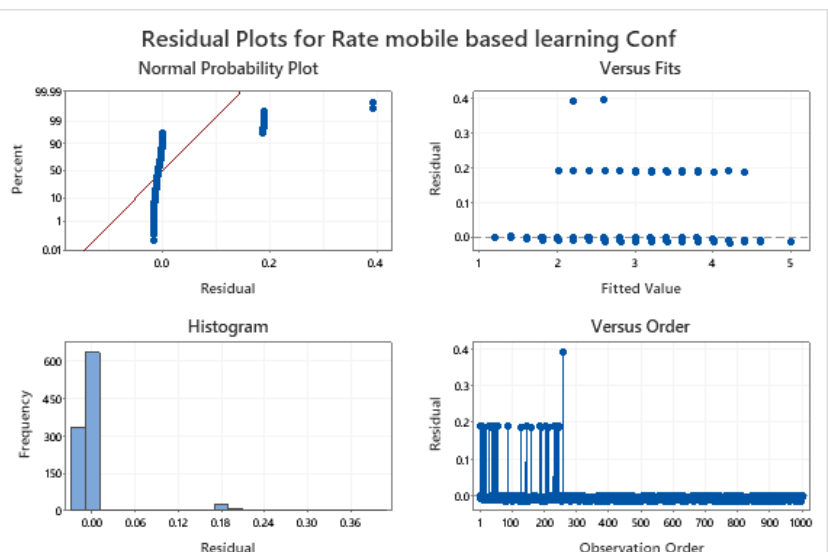

Fig 4. Residual Plots for Rate Mobile based Learning Confidence

Table 2. Analysis of variance of Regression
\begin{tabular}{|l|l|l|l|}
\hline S:No & Parameters & F Value & VIF \\
\hline 1 & Location and Reliability & 49616.13 & 1.00 \\
\hline 2 & Seamless and Contextual & 49926.63 & 1.01 \\
\hline 3 & Learner Centric & 52833.90 & 1.00 \\
\hline 4 & Collaborative & 51651.06 & 1.00 \\
\hline 5 & Interactive and Dynamic & 49622.60 & 1.00 \\
\hline
\end{tabular}

The $\mathrm{R}$ squared adjusted value for the analysis is $99.6 \%$. From Table 2, it can be noted that variance Inflation Factor is less than 5 for all inputs parameters. Subsequently, it means that there is absence of collinearity. Here, all have $p$ value as 0.00 , and hence, the F Value is compared for the inputs and the best three are selected. They are the best among all from the tables and include Learner Centric > Collaborative> Seamless and Contextual as shown in Table 2.

For further predictive study with the neuro fuzzy modelling, the data of Learner Centric, Collaborative, and Seamless and Contextual have been considered. 


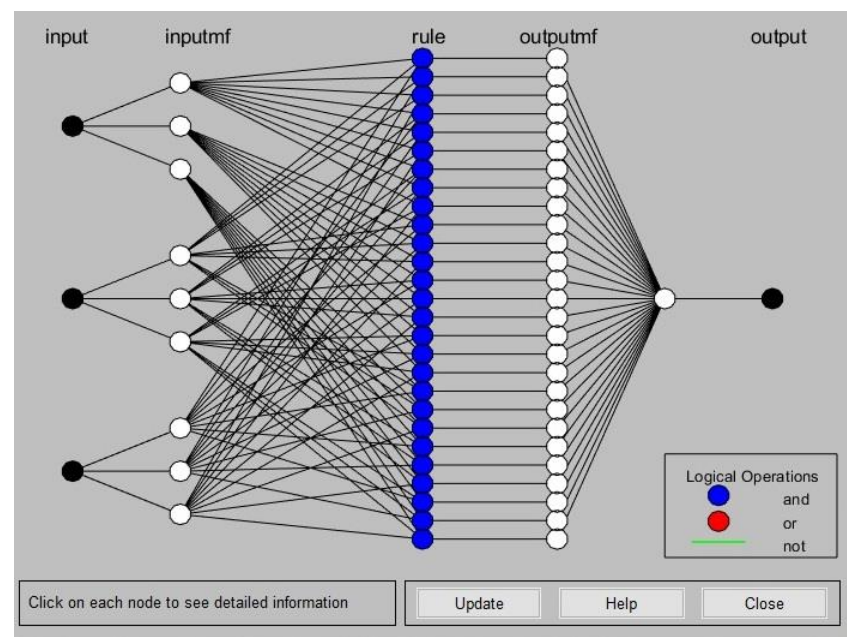

Fig 5. Neuro Fuzzy Structure

Neuro fuzzy structure displays three input nodes on the left side and the final predicted output on the right side. Bell MF Function is used for creating Neuro-fuzzy structure and three membership functions are used to represent each input.

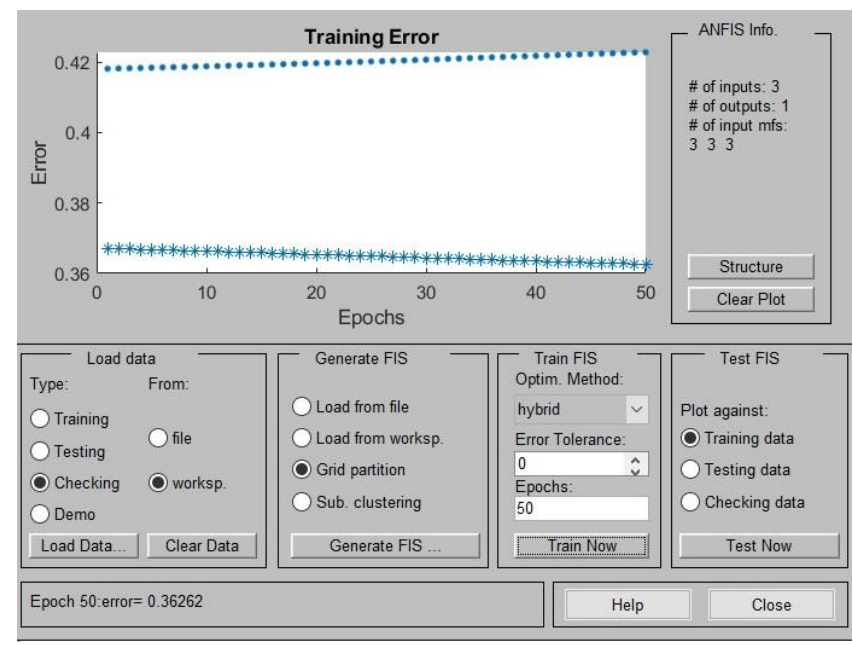

Fig 6. Training of the Neuro Fuzzy Prediction Model

Training data are $70 \%$ of the total data and the testing data are taken as $20 \%$ whereas the reaming $10 \%$ is dedicated for checking data. Training is done with grid partition method and after various trails; it is observed that consistent results are obtained at the iteration of less than 60. Mean square error of 0.2 to 0.3 is observed in the run.

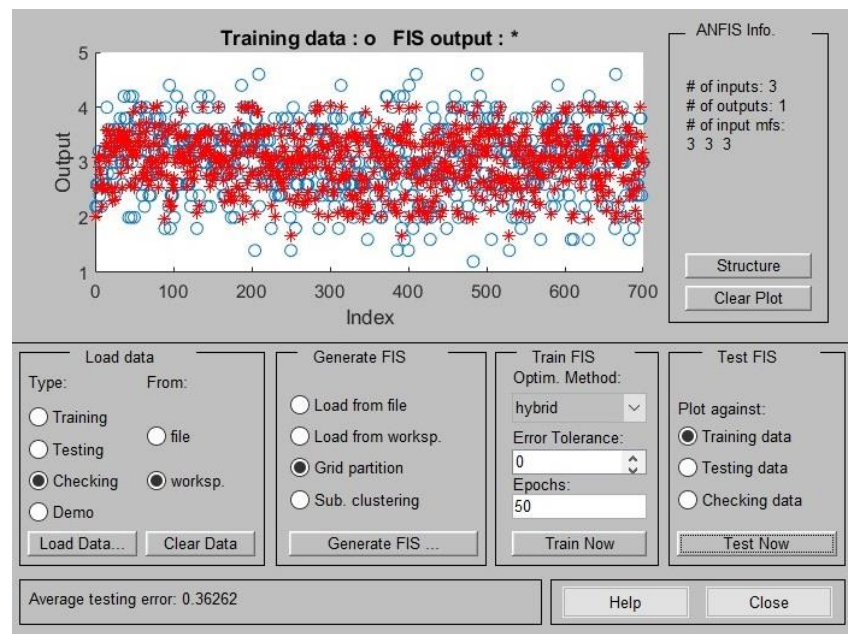

Fig 7. Plot of trained versus raw data

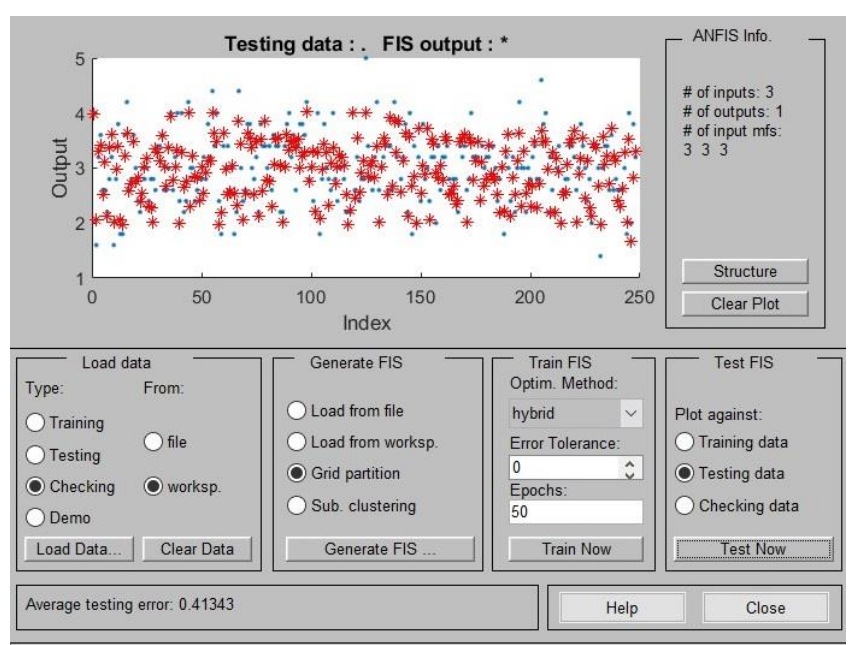

Fig 8. Plot of testing data

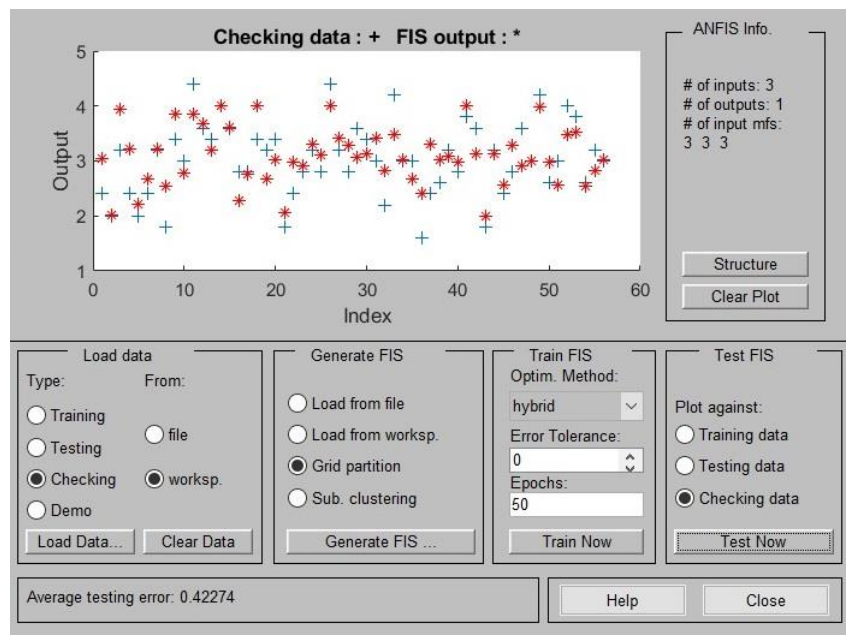

Fig 9.Plot of Checking data 


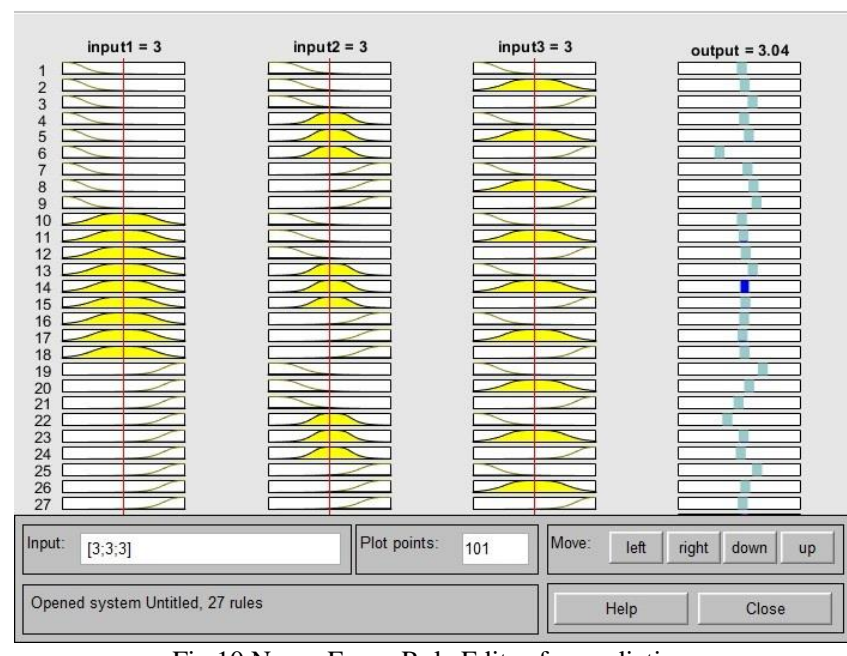

Fig 10.Neuro Fuzzy Rule Editor for prediction

The fuzzy rules developed by the neuro fuzzy system are shown and the sliders enable the prediction of output. The Characteristics of the outcome are shown in 3D Model as shown in Figures 11-13. Here, the input 1 is learner centric, input 2 is seamless and contextual, input 3 is collaborative and the output is confidence.

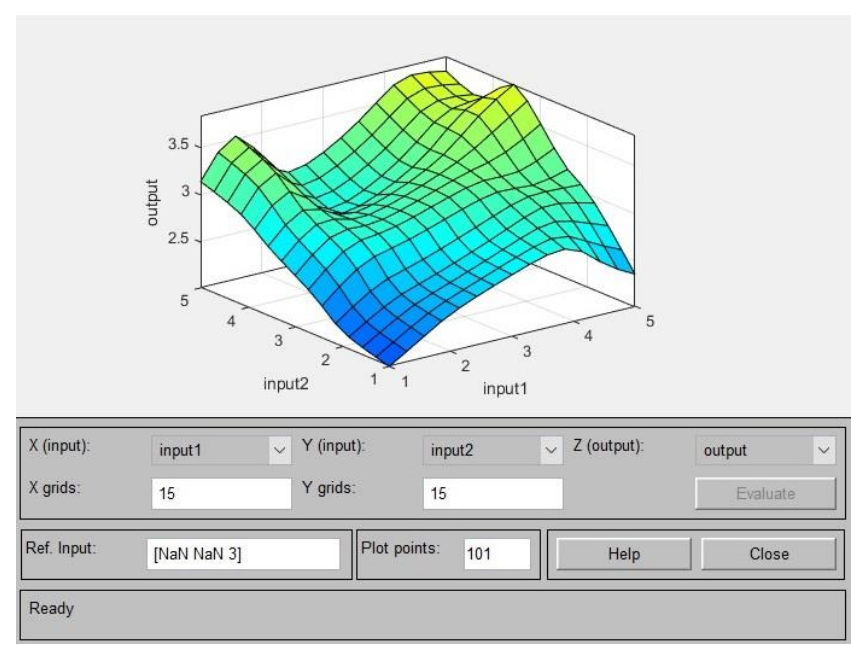

Fig 11.Characteristics of Seamless and Contextual,Learner Centric versus Confidence

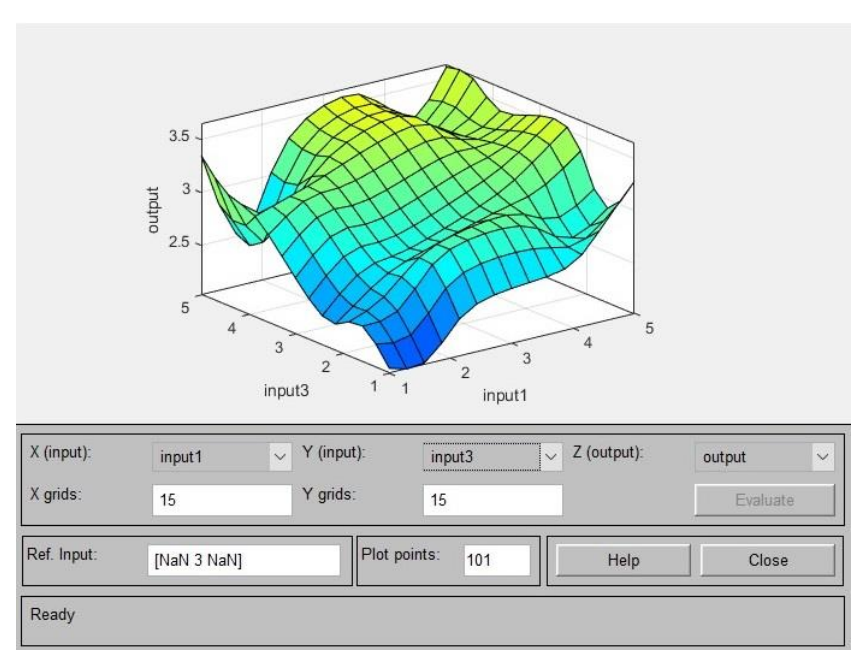

Fig 12.Seamless and Contextual,Collaborative versus Confidence

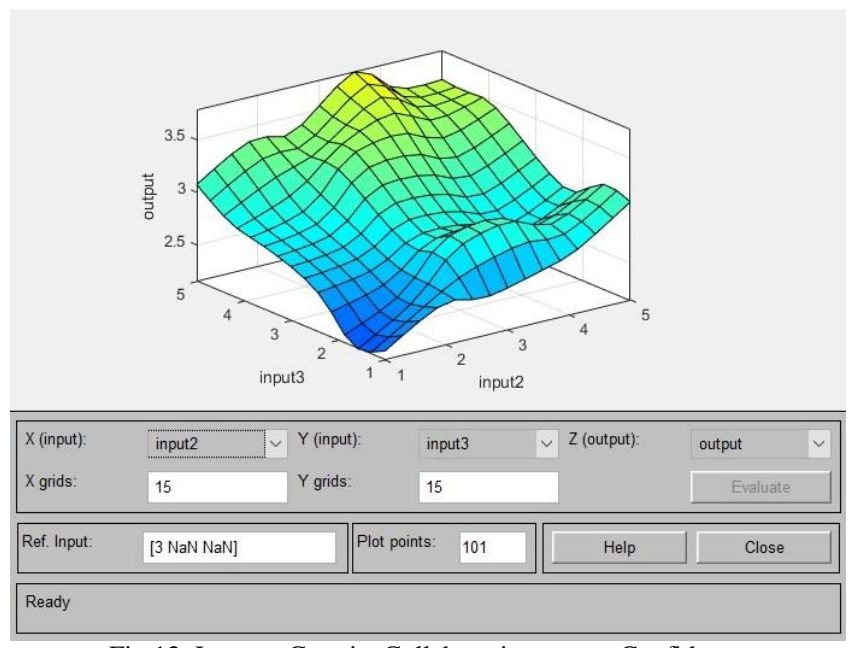

Fig 13, Learner Centric, Collaborative versus Confidence

\section{Conclusion}

All the parameters are found to be equally prominent in influencing the confidence. Among this, most important parameter is the learner centric. For the purpose of developing the prediction model, a stepwise regression has been carried out and the three major factors such as Learner centric, Seamless and Contextual and Collaborative are identified. Based on these three major factors, a neuro fuzzy model has been developed. This prediction model enables to study the changes in confidence of students based on the three major factors. It is concluded that the study analysis depicts that the Learner centric is more significant parameter when mobile infographic pedagogy is utilized. This prediction model would be helpful to other institutes to study the behaviour and pattern of the student confidence based on the parameters investigated.

\section{Reference}

[1] M.L.Crescente and D.Lee, (2011) Critical issues of mlearning:design models, adoption processes, and future trends.,Journal of the Chinese institute of industrial engineers,vol.28,no.2, pp.111-123.

[2] T.Kim,J.Y. Cho and B.G.Lee, (2013) Evolution to smart learning in public education:A case study,Korean public education.Open and Social Technologies for Networked Learning, vol.395,pp.170-178.

[3] J.Lee,H.Zo and H.Lee, (2014)Smart learning adoption in employees and HRD managers, British Journal of Educational Technology,vol.45,no.6,pp.1082-1096.

[4] A. Middleton, (2015) Smart learning:Teaching and learning with smart phones and tablets in post- 
compulsory education, Media-enhanced learning special interest group and Sheffield Hallam University Press.

[5] T.E.Lias and T.Elias, (2011)Learning analytics :The definitions,the processes, and the potential.[Online]. Available:http://learning analytics.net/ Learning Analytics Definitions Processes Potential.pdf.

[6]G.Hwang ,(2014)Definition,frame work and research issues of smart learning environments: A contextaware ubiquitous learning perspective,"Smart Learning Environments,vol.1, no.1,pp.1-14.

[7] Z. T. Zhu, M. H. Yu and P. Riezebos, (2016)A research framework of smart education.," Smart Learning Environment,vol.3, no.4, p.4.

[8] R.Huang,J. Yang and Y.Hu, (2012) From digital to smart:The evolution and trends of learning environment,'Open Education Research,vol.1,p.7584.

[10]K.Scott and R.Benlamri, (2010)Context-aware services for smart learning spaces,"Learning Technologies,vol.3, no.3, pp.214-227.

[11] M. Kearney, S. Schuck, K. Burden and P. Aubusson, (2012) Viewing mobile learning from a pedagogical perspective,"Research in Learning Technology,vol.20,p.14406.

[12]J. Traxler, (2007)Defining,discussing, and evaluating mobile learning:The moving finger writes and having write...,'InternationalReviewofResearchinOpenandDi stanceLearning, vol.8, no.2, p. 1492-3831,2007.

[13]R. J. Kannan, P. Punithavathiand N. Sambandam, (2018) Technology Adoption Models-Adoption of ICT in Educational Institutions in India,"in 2018 World Engineering Education Forum-Global Engineering Deans Council(WEEF- GEDC).

[14] J.Zhang ,(2010) Technology supported learning innovation in cultural context,"Educational Technology Research and Development,vol.58,p.229243.

[15]K.Burden and M.Kearney,(2016) Future scenarios for mobile science learning, Research in Science Education,vol.46,no.2,p.287-308.

[16]M.Kearney,K.Burden and T.Rai, (2015)Investigating teachers adoption of signature pedagogies ,Computers\& Education,vol.80,p.48-57.

[17]J.Potts,N.Moore and S.Sukittanon, (2011) Developing mobile learning applications for electrical engineering courses,in 2011Proceedings of IEEE South east con.

[18] E.Redondo ,D.Fonseca, A.Sánchez and I.Navarro,(2013) New strategies using hand held augmented reality and mobile learning-teaching methodologies,in architecture and building engineering degrees, in Procedia Computer Science.

[19]Y.Li and L.Wang, (2018)Using iPad-based mobile learning to teach creative engineering within a problem- based learning pedagogy,Education and Information Technologies,vol.23,no.1,pp.555-568.

[20]R.K.Mallya and B.Srinivasan,(2019) Impact of Mobile Learning in the Cloud on Learning Competencies of
Engineering Students,'International Journal of Online Engineering,vol.15,no.9, pp.80-87.

[21]A.Peramunugamage,H.Usoof and J.Hapuarachchi,(2019) Moodle Mobile Plugin for Problem-Based Learning(PBL)in Engineering Education,"IEEE Global Engineering Education Conference(EDUCON).

[22] Radhakrishnan Nair, Radeep Krishna and Ramrao, Nagaraj and Sivapragasam, C and Pothiraj, Sivakumar, (2019) Digital Pedagogy for Skill Development of Engineering Faculty to Solve the Grand Challenges Proceedings of International Conference on Digital Pedagogies (ICDP) 2019, Available at SSRN: https://ssrn.com/abstract=3377630 or http://dx. doi.org/10.2139/ssrn.3377630

[23] Lisa J. Merlo, Amanda M. Stone, Alex Bibbey, (2013) Measuring Problematic Mobile Phone Use: Development and Preliminary Psychometric Properties of the PUMP Scale, Journal of Addiction, vol. 2013, 7. 